\title{
Thermocatalytic membrane distillation for clean water production
}

\author{
Katarzyna Janowska (iD) ${ }^{1}$, Vittorio Boffa (iD ${ }^{1 凶}$, Mads Koustrup Jørgensen (iD) , Cejna Anna Quist-Jensen (iD) , Fabien Hubac ${ }^{1}$, \\ Francesca Deganello (iD ${ }^{2}$, Fabrício E. Bortot Coelho (iD ${ }^{3}$ and Giuliana Magnacca ${ }^{3,4}$
}

Natural water bodies and treated wastewaters contain an increasing variety of organic micropollutants with a negative impact on ecosystems and human health. Herein, we propose an integrated process based on membrane distillation and advanced oxidation, in which thermal energy is simultaneously used to drive the permeation of pure water through a hydrophobic membrane and to activate the generation of reactive oxygen species by a thermocatalytic perovskite, namely Ce-doped strontium ferrate. At a feed temperature of $65^{\circ} \mathrm{C}$, our thermocatalytic distillation apparatus can effectively retain and degrade bisphenol A, as model pollutant, while producing distilled water at the constant rate of $1.60 \pm 0.03 \mathrm{~L} \mathrm{~h}^{-1} \mathrm{~m}^{-2}$, over four continuous runs. Moreover, the membrane makes degradation faster by concentrating the pollutant during filtration. Our technology is effective in the production of pure water without creating a toxic concentrate, it relies on simple process design, and it does not require high pressure or additional chemicals. In addition, it can potentially work continuously driven by renewable thermal energies or waste heat.

npj Clean Water (2020)3:34; https://doi.org/10.1038/s41545-020-00082-2

\section{INTRODUCTION}

The increasing worldwide contamination of water systems caused by industrial development, climate change, population growth and over-consumption is one of the crucial environmental problems humanity is facing. Thousands of organic compounds which are often present in water at low concentrations (typically $\mathrm{ng} \mathrm{L}^{-1}$ or $\left.\mu \mathrm{g} \mathrm{L}^{-1}\right)^{1}$ have become of significant concern, as they have been recognized as a major risk for humans, wildlife, and environment ${ }^{2-4}$. These contaminants of emerging concern are essentially pharmaceuticals, personal care products, steroid hormones, surfactants, industrial chemicals and pesticides, and their abatement cannot be achieved by the conventional physicochemical and biological treatments ${ }^{5-8}$.

In this context, alternative treatments have been proposed for polluted wastewater streams. Among them, membrane filtration and advanced oxidation are gaining increasing attention, as they are highly effective in removing organic pollutants from water systems. Pressure-driven membrane filtration methods, such as nanofiltration and reverse osmosis, are well-established ${ }^{9-11}$, but fouling and creation of toxic concentrates remain major drawbacks ${ }^{12,13}$. On the other hand, advanced oxidation processes ${ }^{14-16}$, which are based on the generation of reactive oxygen species, offer the advantage of ideally mineralizing recalcitrant organic pollutants instead of simply concentrating them in the retentate. However, these processes often require substantial energy and/or chemical input, and their efficiency is limited by the high dilution of the micropollutants and by the non-toxic natural organic matter, which is typically present at high concentrations in wastewater and acts as radical scavenging ${ }^{17}$. The synergistic integration of advanced oxidation and membrane filtration can bring obvious benefits, because one method complements the advantages and overcomes the challenges of the other. For instance, nanofiltration has been proposed in combination with Fenton $^{18}$, photo-Fenton ${ }^{19,20}$, and photocatalysis ${ }^{21,22}$ to concentrate pollutants, thus improving degradation kinetics, while organics in the concentrate stream are fully mineralized. However, integrated photocatalytic-membrane systems are still complex and expensive for an implementation on a real scale, since they need to be activated by exposure to light with proper wavelength $^{23}$. Therefore, their application cannot be extended to the existing wastewater treatment plants, which require technologies with low investment costs, low-energy consumption, high water productivity, and easy operation ${ }^{24}$.

Here we present a novel process for simultaneous membrane distillation (MD) and thermocatalytic destruction of a model organic pollutant in the concentrate stream. This novel process is based on the integration of two emerging technologies for water treatment, namely membrane distillation and advanced oxidation by a thermocatalytic perovskite. In MD, a vapor pressure gradient is established between the hot feed side and the cold permeate side, which are divided by a porous hydrophobic membrane. Consequently, part of the feed vaporizes through the hydrophobic membrane and condenses at the permeate side, while dissolved salts and pollutants are retained. MD operates at much lower hydrostatic pressure than nanofiltration and reverse osmosis, thus allowing for simpler and cheaper filtration modules. In addition, permeability and selectivity of MD membranes are negligibly affected by osmotic pressure and fouling ${ }^{25,26}$. Regarding the advanced oxidation process, certain types of perovskites have been shown to interact with water and dissolved molecular oxygen to form reactive oxygen radicals, which can degrade organic pollutants ${ }^{27}$. Thermocatalytic perovskites have no need for addition of chemicals or light sources and therefore they demonstrate advantages over the other advanced oxidation processes in terms of energy saving and simplicity of operation. For instance, strontium ferrate $\left(\mathrm{SrFeO}_{3-\delta}\right)$ could achieve $83 \%$ mineralization of the endocrine distruptor bisphenol A (BPA) in $24 \mathrm{~h}$, and full decoloration of the organic dye acid orange 8 in

\footnotetext{
${ }^{1}$ Center for Membrane Technology, Department of Chemistry and Bioscience, Aalborg University, Fredrik Bajers Vej 7H, DK-9220 Aalborg East, Denmark. ${ }^{2}$ Istituto per lo Studio dei Materiali Nanostrutturati, Consiglio Nazionale delle Ricerche, Via Ugo La Malfa 153, 90146 Palermo, Italy. ${ }^{3}$ Dipartimento di Chimica, Universitá di Torino, Via P. Giuria 7, 10125 Torino, Italy. ${ }^{4}$ NIS Interdepartmental Centre, Universitá di Torino, Via P. Giuria 7, 10125 Torino, Italy. ${ }^{凶}$ email: vb@bio.aau.dk
} 

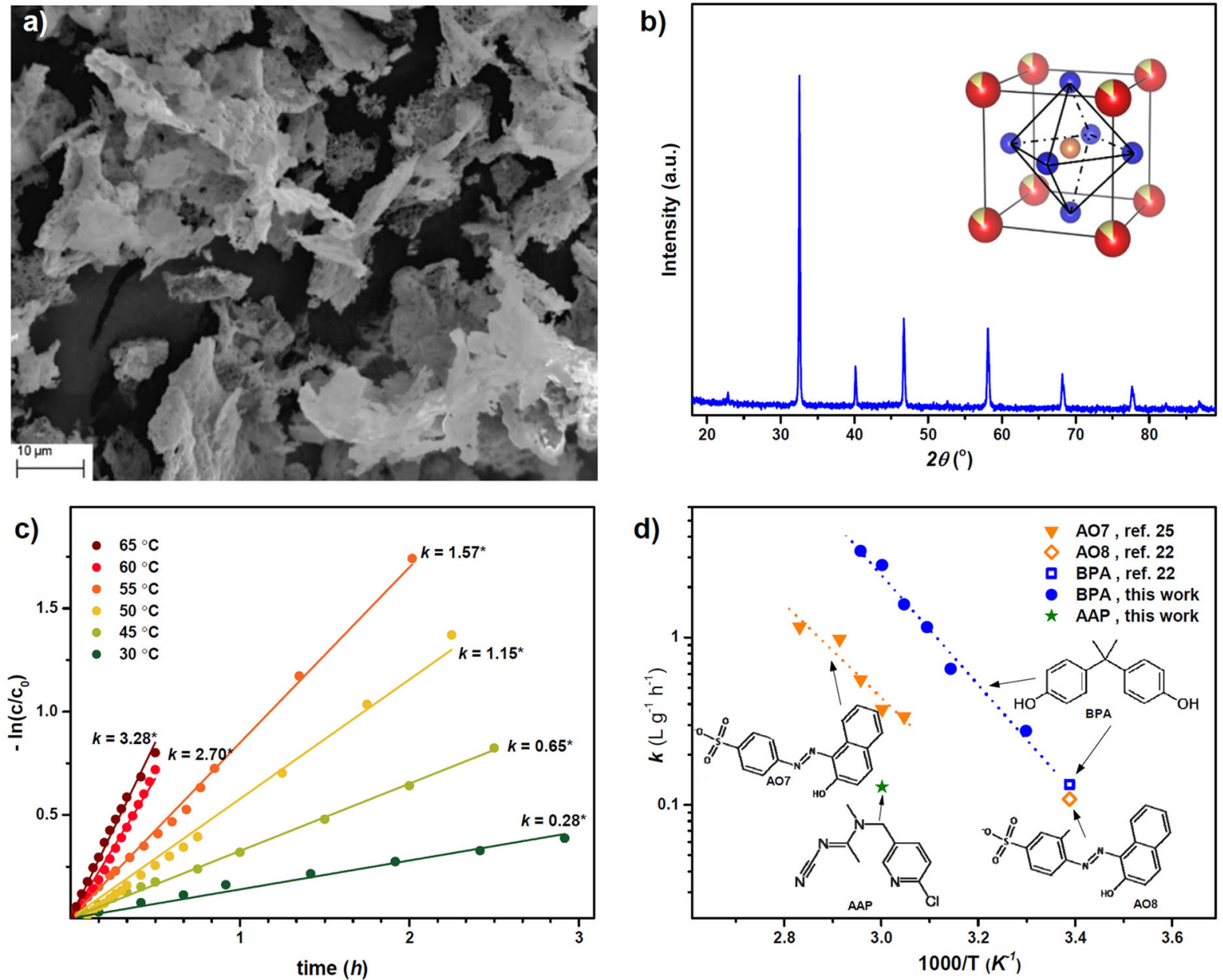

Fig. 1 Thermocatalytic abatement of micropollutants by cubic strontium ferrates. a SEM micrographs of $\mathrm{Sr}_{0.85} \mathrm{Ce}_{0.15} \mathrm{FeO}_{3-\delta}(\mathrm{CSF})$ after calcination at $1000^{\circ} \mathrm{C}$ and $\mathbf{b}$ the correspondent X-ray diffractogram. The image of the cubic perovskite structure as calculated by Rietveld refinement of the diffraction data is depicted in the right-up corner (the iron octahedral site of the $\mathrm{Sr}_{0.85} \mathrm{Ce}_{0.15} \mathrm{FeO}_{3-\delta}$ perovskite is highlighted, whereas the orange, red, yellow, and blue spheres indicate iron, strontium, cerium, and oxygen atoms, respectively); c influence of temperature on the degradation of bisphenol A (initial concentration $c_{0}=10 \mathrm{mg} \mathrm{L}^{-1}$ ) by $\mathrm{Sr}_{0.85} \mathrm{Ce}_{0.15} \mathrm{FeO}_{3-\delta}\left(0.50 \mathrm{~g} \mathrm{~L}^{-1}\right)$ and correspondent apparent rate constants, $k\left(\mathrm{~L} \mathrm{~g}^{-1} \mathrm{~h}^{-1}\right)$; d temperature-dependence of kinetic constants for the abatement of model micropollutants by cubic strontium ferrates: bisphenol A (BPA), acid orange 7 (AO7), acid orange 8 (AO8), and acetamiprid (AAP).

$60 \mathrm{~min}^{28}$. The redox-active cubic structure of strontium ferrate can be stabilized by cerium-doping ${ }^{29,30}$. Thus, Tummino et al. ${ }^{31}$ used $\mathrm{Sr}_{0.85} \mathrm{Ce}_{0.15} \mathrm{FeO}_{3-\delta}$ (cerium-doped strontium ferrate, CSF) to fully mineralize the organic dye acid orange 7 at temperatures ranging from 55 to $80^{\circ} \mathrm{C}$ in few hours, in the dark and without adding chemicals. In our work, CSF was combined with MD to simultaneously degrade BPA while recovering distilled water. BPA was chosen as a model compound, because it is a common micropollutant ${ }^{32}$ with a well-documented endocrine-disrupting activity and toxicity ${ }^{33}$. In this work, we heated the water contaminated by BPA at mild temperatures $\left(30-65^{\circ} \mathrm{C}\right)$ to facilitate the degradation process by CSF and to drive steam through a hollow fiber polypropylene MD membrane, simultaneously. The membrane retained both pollutant and thermocatalyst while producing distilled water, thus improving the degradation kinetics and allowing the thermocatalyst to be reused for several degradation cycles.

In a general perspective, thermocatalytic MD represents a new method for obtaining high purity distillate from contaminated waters, while also reducing the toxicity posed by organic compounds in the concentrate stream. The process design is simple, because it does not require high pressure, external light sources, or additional chemicals, and to the extent that MD is commercially scalable as a water treatment technology, so should be thermocatalytic MD. The process can be easily operated, because heat drives both thermocatalytic degradation of the pollutants and the permeation of distilled water through the membrane. Although part of this thermal energy is lost along the membrane module, energy costs can be compensated by using alternative heating sources, such as solar, geothermal, or lowgrade waste heat from process streams $\mathrm{s}^{34,35}$. Moreover, thermocatalytic MD can be applied to hot streams of polluted water generated by the chemical and the petrochemical industry.

\section{RESULTS}

Thermocatalytic abatement of micropollutants

Thermocatalytic CSF was prepared by solution-combustion synthesis $^{29,31}$, because this method can yield perovskites with welldefined properties ${ }^{36}$. SEM analysis (Fig. 1a) shows that our thermocatalytic powder consists of flakes with lateral dimension ranging from 1 to $30 \mu \mathrm{m}$ and thickness smaller than $0.2 \mu \mathrm{m}$, as reported previously for CSF synthetized with the same method ${ }^{31}$. Such type of particles can easily be retained by membranes for microfiltration and MD. In addition, light scattering analysis revealed that when dispersed in water these particles tend to 

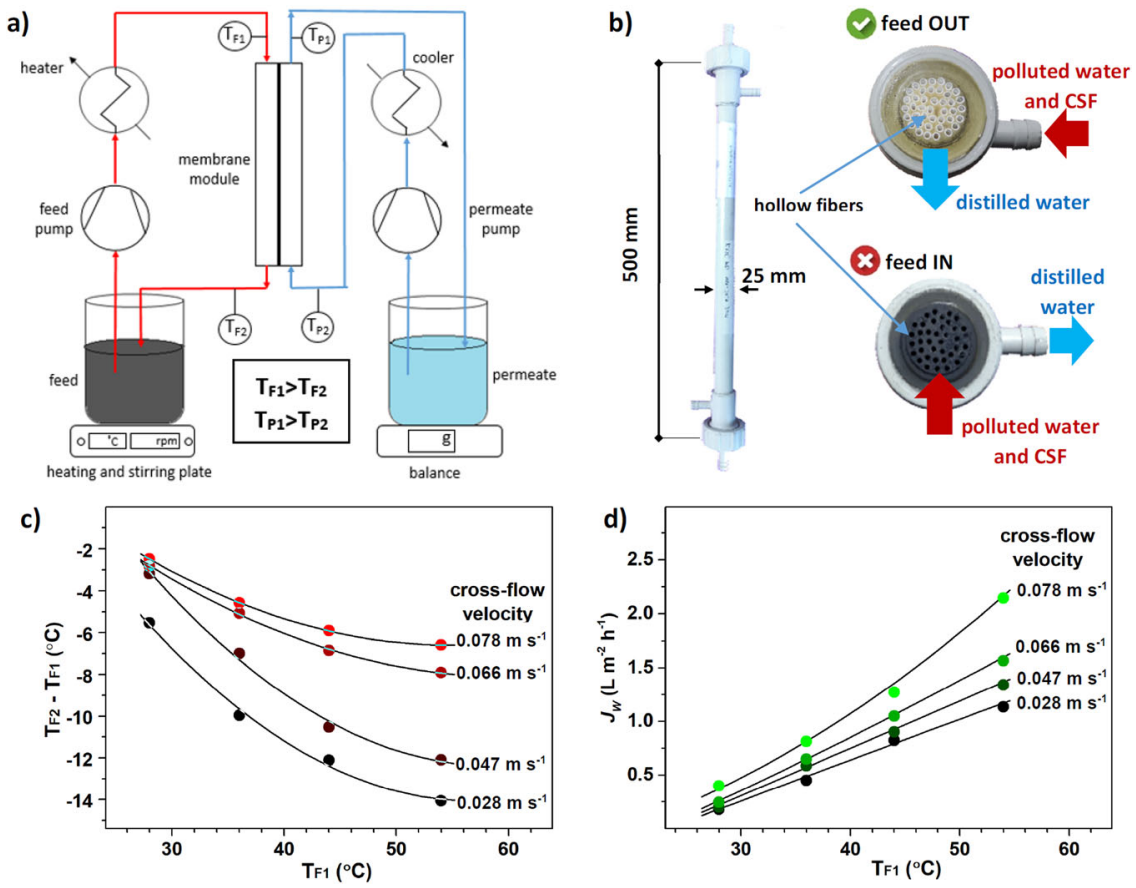

Fig. 2 Production of clean water by membrane distillation. a Scheme of the membrane distillation (MD) apparatus used in our experiments. The membrane module b consists of 40 porous polypropylene hollow fibers (length: $500 \mathrm{~mm}$, inner diameter: $1.8 \mathrm{~mm}$, wall thickness: $120 \mu \mathrm{m}$, and pore size: $0.2 \mu \mathrm{m}$ ). c The section of two membrane modules after being used with the correct flow configuration (feed OUT) and after being clogged by CSF particles (feed IN). $T_{\mathrm{P} 2}$ was kept constant at $\sim 17^{\circ} \mathrm{C}$ in all the experiments, while $T_{\mathrm{F} 1}$ and the cross-flow velocity were varied. The cross-flow velocity has an impact on $\mathbf{c}$ the drop of the feed temperature along the module and therefore $\mathbf{d}$ on the rate of water permeation through the membrane. In the plots, lines represent modeled values whereas bullets are measured values.

form aggregates with sizes of several microns, which makes it easy to recover them during filtration (Supplementary Fig. 1). The CSF particles also show a large density of macropores, which were presumably formed by gas-release during the combustion in the synthesis process. ${ }^{36}$ The specific surface area of the material is $25 \mathrm{~m}^{2} \mathrm{~g}^{-1}$, as measured by nitrogen adsorption (Supplementary Fig. 2). EDS analysis indicates a Ce:Fe atomic ratio of $0.15: 1$, confirming the cerium loading expected from the stoichiometry of the precursors' solution used for the synthesis. Figure $1 \mathrm{~b}$ reports the X-ray diffractogram of CSF, which indicates that all the cerium ions have been incorporated in one crystal phase with cubic structure $(P m-3 m)$. Particle size and shape, composition, porosity and crystal structure well match the $\mathrm{Sr}_{0.85} \mathrm{Ce}_{0.15} \mathrm{FeO}_{3-\delta}$ perovskite previously reported by using the same preparation methodol$\operatorname{ogy}^{29,31}$, demonstrating the high reproducibility of the synthesis method.

The ability of the CSF to degrade BPA was investigated in temperatures ranging from 30 to $65^{\circ} \mathrm{C}$ and thermocatalyst concentrations $\left(C_{\mathrm{CSF}}\right)$ between 0.15 and $1.0 \mathrm{~g} \mathrm{~L}^{-1}$. Figure $1 \mathrm{c}$ shows the data obtained for the tests with $C_{\mathrm{CSF}}=0.50 \mathrm{~g} \mathrm{~L}^{-1}$. It was observed that CSF is highly active in the degradation of the BPA. Literature suggests that CSF can generate oxygen reactive species $^{28,31}$, but more investigation is required to determine the degradation mechanism. The BPA degradation process follows an apparent first-order kinetic with respect to catalyst and BPA concentrations. The rate constants are plotted as a function of the temperature in Fig. 1d. The observed degradation rate constant can be expressed according to following equation:

$k=a \cdot C_{\mathrm{SCF}} \cdot \exp \left(-\frac{E_{\mathrm{a}}}{R \cdot T}\right)$

In our BPA degradation experiments the frequency constant (a) and the apparent activation energy $\left(E_{\mathrm{a}}\right)$ resulted to be $(1.6 \pm 0.1) \times$ $10^{10} \mathrm{~L} \mathrm{~g}^{-1} \mathrm{~h}^{-1}$ and $63 \pm 4 \mathrm{~kJ} \mathrm{~mol}^{-1}$, respectively.
We determined BPA abatement rate constants with a trend consistent with the results that Leiw et al. ${ }^{28}$ obtained with cubic strontium ferrate $\left(\mathrm{SrFeO}_{3-\delta}\right)$ : i.e. $k=0.13 \mathrm{Lg}^{-1} \mathrm{~h}^{-1}$, at room temperature. Moreover, cubic strontium ferrates have also proven their activity in the degradation of other model micropollutants, as shown in Fig. 1d. Leiw et al. ${ }^{28}$ reported the ability of cubic $\mathrm{SrFeO}_{3-\delta}$ to degrade the organic dye Acid Orange 8 at room temperature, after one day exposure (at room temperature $k=$ $0.11 \mathrm{~L} \mathrm{~g}^{-1} \mathrm{~h}^{-1}$ ). Tummino et al. ${ }^{31}$ performed a kinetic study of the degradation of Acid Orange 7 with CSF, determining an activation energy of $52 \mathrm{~kJ} \mathrm{~mol}^{-1}$. Moreover, our CSF was able to degrade the pesticide Acetamiprid at a rate similar to the other pollutants $(k=$ $0.13 \mathrm{Lg}^{-1} \mathrm{~h}^{-1}$ at $60^{\circ} \mathrm{C}$ ).

\section{Water purification by MD}

In this work, we tested BPA degradation by CSF during filtration in a direct-contact MD apparatus, whose scheme is depicted in Fig. 2a. The hollow fiber membrane module used for our tests is shown in Fig. 2b. The module can function either by pumping the feed inside the hollow fibers and the permeate on the shell side or vice versa. However, when the feed solution flowed through the hollow fibers, the CSF powder clogged them after few hours of filtration. Therefore, all our tests were run with the feed solution flowing outside the hollow fibers, i.e. at the shell side. The rate of permeation of water through the membrane $\left(J_{\mathrm{W}}\right)$ was investigated at various feed temperatures and cross-flow velocities, while no pressure gradient was applied across the walls of the hollow fibers. On the contrary, a temperature gradient was established between the feed and the permeate side. However, this temperature gradient is not constant along the membrane module. Indeed, the feed temperature drops while flowing in the module due to two main factors: (i) the vaporization of water through the membrane pores and (ii) the convective heat transfer via the membrane walls. This drop in temperature $\left(T_{\mathrm{F} 2}-T_{\mathrm{F} 1}\right)$ can 


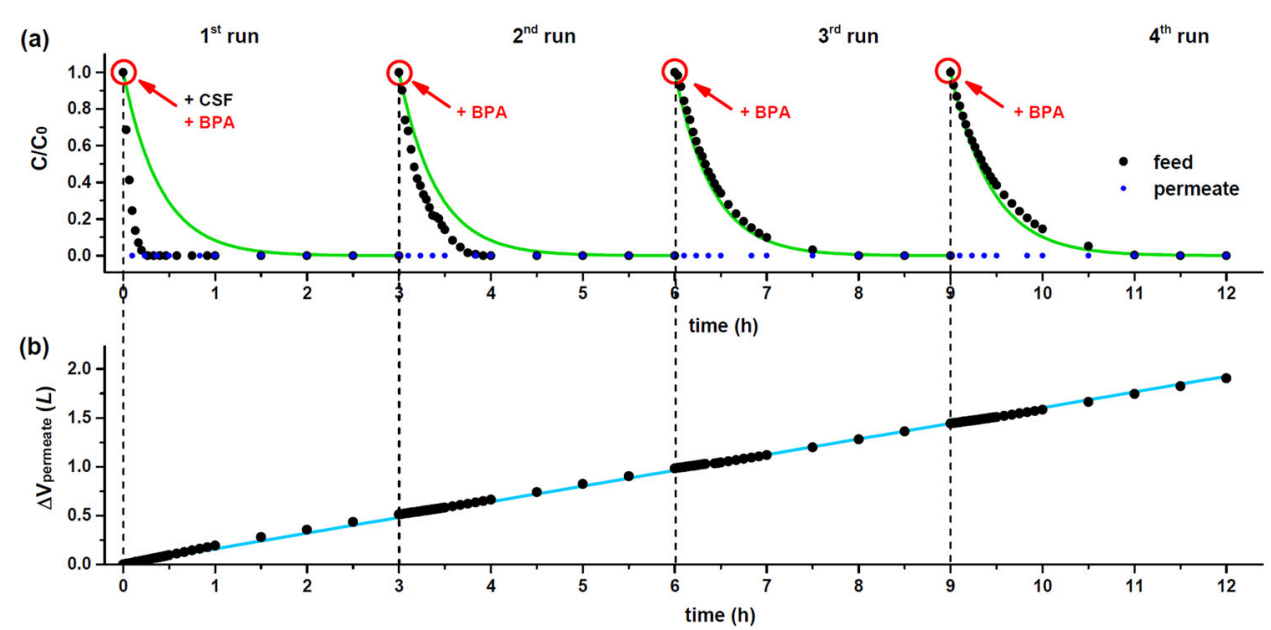

Fig. 3 Simultaneous degradation of BPA and production of distilled water by thermocatalytic membrane distillation with $\mathrm{Sr}_{\mathbf{0 . 8 5}} \mathrm{Ce}_{\mathbf{0 . 1 5}} \mathrm{FeO}_{3-\delta}$ (CSF), a Concentration of BPA in the feed and in the permeate relatively to the starting BPA concentration in the feed tank, i.e. $C_{0}=10 \mathrm{mg} \mathrm{L}^{-1}$, during four consecutive runs of thermocatalytic distillation in our apparatus, green lines represents BPA concentration in the feed, as calculated by our catalytic membrane distillation model (Supplementary Information, p. 4); b distilled water produced by our apparatus during the four runs, the blue line indicates the volume of permeated water over the entire thermocatalytic distillation experiment, as calculated by Eq. (2).

be reduced by increasing the cross-flow velocity (Fig. 2c). For instance, by setting $T_{\mathrm{F} 1}$ to $54.0^{\circ} \mathrm{C}$, the feed temperature after leaving the module $\left(T_{\mathrm{F} 2}\right)$ is 40.0 and $48.4^{\circ} \mathrm{C}$ for cross-flow velocities of 0.028 and $0.078 \mathrm{~m} \mathrm{~s}^{-1}$, respectively. In general, high cross-flow velocities are beneficial to preserve a water vapor pressure gradient across the membrane by reducing temperature drop from inlet to outlet of the filtration module and by mitigating temperature polarization at the membrane surface ${ }^{37-45}$. This results in higher water permeation rates (Fig. 2d). We observed no significant differences of water permeation rates in the experiments performed in the presence or in the absence of CSF powder (Supplementary Fig. 3) and our water fluxes are comparable with those reported in literature with the same membrane modules ${ }^{46}$, suggesting that the CSF powder remains suspended in the solution feed and no cake layer is formed on the membrane surface. Based on these data, we developed an empirical model, which describes the temperature dependency of permeate flux. For instance, at a cross velocity of $0.047 \mathrm{~m} \mathrm{~s}^{-1}$, permeate flux can be described by Eq. (2) (correlation coefficient with experimental data $\left.R^{2}=0.991\right)$, where $\Delta T$ represents the temperature difference $[K]$ between the water in the feed beaker and the water in the permeate beaker.

$J_{W}=0.0022 \cdot \Delta T^{1.687}$

Hence, by combining Eq. (1) and permeation data, we constructed a simple model for designing thermocatalytic MD for BPA abatement in our apparatus. A detailed description of this model is given in the Supplementary Information.

\section{BPA abatement by thermocatalytic MD}

The use of CSF in the MD apparatus (Fig. 2a) for simultaneous BPA abatement and clean water production is here evaluated. The experimental procedure was the following: at first, $1.80 \mathrm{~L}$ of a feed solution containing BPA $\left(C_{0}=10 \mathrm{mg} \mathrm{L}^{-1}\right)$ in deionized water was heated and kept at $65^{\circ} \mathrm{C}$. In the permeate reservoir, $0.50 \mathrm{~L}$ of distilled water was cooled by a water bath at $17^{\circ} \mathrm{C}$. The membrane cross-flow velocity was set to $20 \mathrm{~L} \mathrm{~h}^{-1}$ on both feed and permeate sides. Once the target temperatures were reached in both feed and permeate reservoirs, $1.8 \mathrm{~g}$ of CSF powder was added at once to the feed. The amount of water permeated through the membrane during the experiment was measured by a scale under the permeate beaker. Samples were taken at regular time intervals and analyzed by HPLC to determine BPA concentrations in the feed and in the permeate. After running the thermocatalytic distillation for $3 \mathrm{~h}$, a new cycle was started. Thus, the required amounts of distilled water and BPA was added to the feed in order to reestablish the initial feed volume $(1.80 \mathrm{~L})$ and the BPA concentration $\left(10 \mathrm{mg} \mathrm{L}^{-1}\right)$.

Figure $3 a$ shows the relative concentration of BPA $\left(C / C_{0}\right)$ plotted as a function of time over four consecutive runs. The membrane showed good retention of BPA along all the experiments, since the concentration of BPA in the permeate was always below the detection limit $\left(0.05 \mathrm{mg} \mathrm{L}^{-1}\right.$ in our analytical method, implying a BPA retention $>99.5 \%$ at the start of each run). Such resistance to wetting for this membrane module is consistent with our previous results ${ }^{46,47}$. CSF was added at the feed side only at the beginning of the first run. Experimental data in the third and fourth runs fits well to our thermocatalytic MD model, while the observed degradation rates in the first and second runs were faster than expected. This discrepancy is probably caused by the fact that, at the beginning, all the CSF powder is dispersed in the water inside the feed beaker, which has a temperature of $65^{\circ} \mathrm{C}$. Then, part of the CSF powder migrates together with the feed solution inside the membrane module, where the average temperature of the water at the shell side is about $45^{\circ} \mathrm{C}$, as we have discussed already, thus reducing the degradation rate of BPA. Our model takes into account this temperature drop in the membrane modules, but our apparatus reaches steady-state only after a few hours of operation, that is, from the third run in Fig. 3a. We performed a control experiment in the absence of CSF, observing an increase in BPA concentration at the feed side during filtration (Supplementary Fig. 4). Furthermore, as already mentioned, the presence of the thermocatalyst does not affect the production rate of distilled water through our membrane and in Fig. 3b we can observe that the permeate production $\left(J_{\mathrm{W}}\right)$ was constant during the whole filtration experiment. Indeed, the linear fitting of all the experimental data points allowed to calculate $J_{\mathrm{W}}=1.60 \pm$ $0.03 \mathrm{~L} \mathrm{~h}^{-1} \mathrm{~m}^{-2}\left(R^{2}=0.9997\right)$. Moreover, our model can well predict the water permeation rate under these experimental conditions: $J_{\mathrm{W}}=1.62 \mathrm{~L} \mathrm{~h}^{-1} \mathrm{~m}^{-2}$, according to Eq. (2).

The model was also used to investigate the impact of CSF loading and membrane area on the BPA abatement by thermocatalytic MD. Figure 4 reports our simulations. With no thermocatalytic perovskite (CSF) the BPA is concentrated during filtration. However, Fig. $4 \mathrm{~b}$ shows that such increase in BPA concentration is 

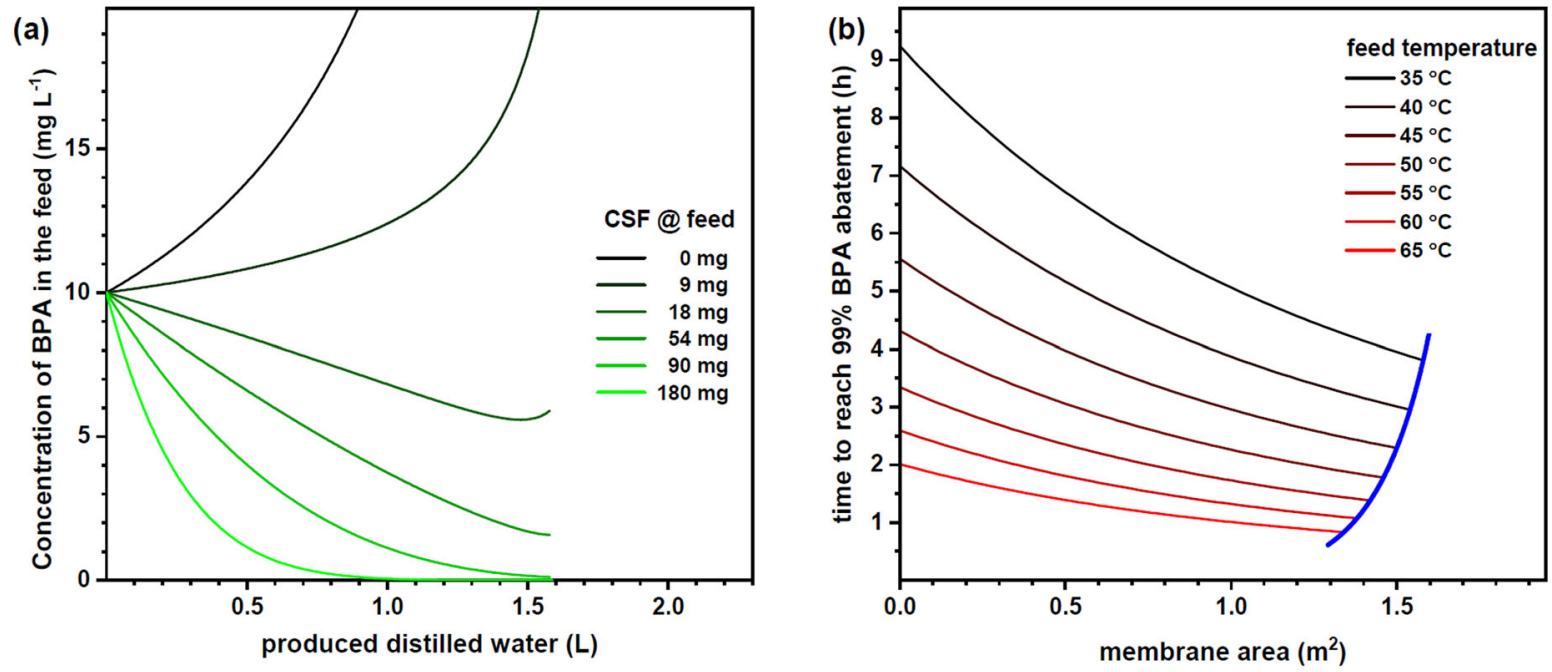

Fig. 4 Simulation of BPA abatement by the thermocatalytic membrane distillation. a BPA concentration in the feed as a function of the produced water at different CSF loadings (feed initial volume: $1.80 \mathrm{~L}$, cross-flow velocity: $0.047 \mathrm{~m} \mathrm{~s}^{-1}$, and temperatures in the feed and permeate beakers: 65 and $15^{\circ} \mathrm{C}$, respectively); $\mathbf{b}$ time needed to reach $99 \%$ degradation of BPA (initial $C_{\mathrm{BPA}}: 10 \mathrm{mg} \mathrm{L}{ }^{-1}$, CSF loading: $1.80 \mathrm{~g}$ ) vs. membrane area at different feed temperatures. The blue line indicates the membrane area above which the permeate flow is so high that $99 \%$ BPA abatement cannot be reached before draining all the water in the feed beaker.

avoided by adding $54 \mathrm{mg}$ of CSF in the feed stream. Furthermore, $1.80 \mathrm{~g}$ of CSF allows achieving $>99 \%$ pollutant degradation while producing $1 \mathrm{~L}$ of water. Figure $4 \mathrm{~b}$ shows the time needed to reach $99 \%$ abatement of BPA in our apparatus at different feed temperatures in the range from 30 to $65^{\circ} \mathrm{C}$, supposing that the area of the distillation membrane could be varied progressively from 0 to about $1.5 \mathrm{~m}^{2}$. The blue line indicates the area at which, based on our simulation, the flow of distilled water through the membrane is faster than the rate of degradation, meaning that there is not enough time to reach $99 \%$ degradation before the feed beaker becomes empty. The graph makes evident the positive influence of larger membrane area on reducing the abatement time, explained by the membrane concentrating the pollutant during its abatement. The positive effect of the membrane is more pronounced at lower temperatures, where the degradation rates are slower. For instance, at $35^{\circ} \mathrm{C} 99 \%$ BPA abatement is achieved in $9.2 \mathrm{~h}$ without membrane, while this time is reduced to $5 \mathrm{~h}$ by applying a membrane with area of $1 \mathrm{~m}^{2}$.

\section{DISCUSSION}

For the first time a thermocatalytic perovskite with formula $\mathrm{Sr}_{0.85} \mathrm{Ce}_{0.15} \mathrm{FeO}_{3-\delta}$ (CSF) was integrated in a MD unit. The new process was investigated in the degradation of BPA as a model water contaminant. A temperature-dependent catalytic behavior was confirmed for the CSF toward BPA degradation and its reusability was established up to four thermocatalytic distillation runs. In comparison with traditional pressure-driven filtration processes as nanofiltration and reverse osmosis, thermocatalytic MD offers the advantages of full BPA rejection, much lower operating pressure and, above all, the production of pure water without creating a toxic concentrate. Moreover, we proved that the combination of MD with CSF has advantages over the CSF batch catalysis. Indeed, the combined process is faster in the degradation of pollutants and it allows the recovery of the catalyst without additional steps, leading to higher clean water throughputs. Compared to photocatalytic membrane systems, the new process has no need of light irradiation and can be simply operated, as both MD and CSF are activated by heat. This is the first attempt to integrate MD with a thermocatalyst and the new technology still presents some challenges. Firstly, despite the kinetic constants for BPA degradation for CSF under dark conditions have the same magnitude of those observed for the traditional $\mathrm{TiO}_{2}$ photocatalysts under UV light ${ }^{48-51}$, our perovskite contains cerium, which makes it intrinsically more expensive than $\mathrm{TiO}_{2}$. Moreover, the perovskite was synthetized by the solutioncombustion method, which is a well-established and reproducible lab-scale procedure. Nevertheless, industrial production of the perovskite would require scale-up optimization. Deganello et al. analyzed this issue and proposed some solutions in a recent review $^{36}$. Second, thermocatalytic materials have been shown to be effective in the abatement of model water pollutants or specific water systems and for operation time not longer than a few days ${ }^{52}$, but the stability of their performances when treating wastewater effluents for several months (as in real applications) still needs to be explored. Third, MD apparatuses demand a substantial amount of thermal energy in order to heat and keep the temperature of the water at the feed side of the membrane, making MD economically viable only in the presence of cheap sources of heat. Despite these challenges, our experimental data allow for envisaging future optimization of the new process, e.g. by coupling MD modules with continuous stirred thank (Supplementary Information, p. 6) or with a fixed-bed thermocatalytic reactor in view of future applications with real water systems, for which the present literature $26,28,52$ supports the feasibility of our technology. Therefore, this work may open the way to a new technology of the treatment of wastewater streams, stimulating the development of thermocatalysts with high-stability and activity for the degradation of a broad spectrum of micropollutants in complex water matrixes, MD units with high water productivity and new design solutions for the integrated system.

\section{METHODS}

CSF synthesis

$1.80 \mathrm{~g}$ strontium (II) nitrate anhydrous (AVOCADO Research Chemicals Ltd, purity 99\%), $4.04 \mathrm{~g}$ iron (III) nitrate nonahydrate (Sigma Aldrich, purity $\geq 98 \%$ ) and $0.65 \mathrm{~g}$ cerium (III) nitrate hexahydrate (Sigma Aldrich, purity 99\%) were dissolved in $200 \mathrm{~mL}$ of distillated water. Then, $7.68 \mathrm{~g}$ citric acid (Carl Roth, purity $\geq 99.5 \%$ ) was added in order to reach a citric acid-to-metal cations ratio of 2 , whereas the reducers-to-oxidizers ratio $(\Phi)$ was regulated at 1.5 through the addition of $9.25 \mathrm{~g}$ of ammonium nitrate (Sigma Aldrich, purity $\geq 99.5 \%$ ) oxidant, according to the valence concepts based on propellant chemistry ${ }^{36}$. The $\mathrm{pH}$ of the solution was adjusted to 6.0 using ammonium hydroxide (Sigma Aldrich, $25 \mathrm{wt} \%$ ), in order to favor citrate 
anions-metal cations complex formation, and the glass beaker was placed on the hot plate and kept at $80^{\circ} \mathrm{C}$ for the evaporation of the water under continuous magnetic stirring. When a sticky gel was obtained, the hot plate was set at the maximum temperature $\left(310^{\circ} \mathrm{C}\right)$ in order to start the gel self-ignition. After the combustion, the as-burned powder was calcined at $1000^{\circ} \mathrm{C}$ for $5 \mathrm{~h}$ with a heating rate of $5^{\circ} \mathrm{C} \mathrm{min}{ }^{-1}$. After calcination, about $2 \mathrm{~g}$ of $\mathrm{Sr}_{0.85} \mathrm{Ce}_{0.15} \mathrm{FeO}_{3-\delta}$ powder was obtained.

\section{CSF characterization}

X-ray diffraction (XRD) measurements were performed on a PANanalytical Empyrean diffractometer, operating at $45 \mathrm{kV}$ and $40 \mathrm{~mA}$, with $\mathrm{Cu} \mathrm{Ka}$ radiation $\left(\lambda=1.5418 \AA\right.$ ). $\mathrm{Sr}_{0.85} \mathrm{Ce}_{0.15} \mathrm{FeO}_{3-\delta}$ was indexed in the Inorganic Crystal Structure Database (ICSD) under code \#249012. CSF morphology was investigated by SEM analysis using a ZEISS EVO 50 XVP microscope with $\mathrm{LaB}_{6}$ source. The samples were mounted on metallic stubs with double-sided conductive tape and ion coated with gold layer by a sputter coater (Baltec SCD 050) for $80 \mathrm{~s}$ under vacuum at a current intensity of $60 \mathrm{~mA}$ to avoid any charging effect. The chemical composition of samples was analyzed by energy-dispersive spectroscopy (EDS) using Oxford EDS INCA (Oxford Instruments). CSF specific surface area and porosity were determined by nitrogen adsorption/desorption isotherms at $\mathrm{N}_{2}$ boiling point using an ASAP2020 gas-volumetric apparatus (Micromeritics). BET and $\mathrm{BJH}$ models were applied to calculate the specific surface area and pore size distribution, respectively. Prior to analyses, the samples were outgassed in vacuum (residual pressure $\sim 10^{-2} \mathrm{mbar}$ ) at $300^{\circ} \mathrm{C}$. Particle size distribution was determined by laser diffraction using a particle size analyzer LS 13320 single-wavelength (Beckman Coulter), with an analysis range from 0.37 to $2000 \mu \mathrm{m}$.

\section{MD setup}

The laboratory set-up was equipped with a Microdyn MD-020-2N-CP hollow fiber membrane module (nominal filtering area $=0.1 \mathrm{~m}^{2}$ ) The set-up consisted of $1 \mathrm{~L}$ glass bottle of feed placed on heating plate with stirrer and $1 \mathrm{~L}$ bottle of permeate placed on balance. Feed and permeate were pumped through a peristaltic pump Masterflex L/S Easy-Load (model 77200-62) from the feed bottle through heater followed by the membrane module and back into the feed tank. The flow rate of pumping was $20 \mathrm{~L}$ $\mathrm{h}^{-1}$. Distilled permeate water was pumped from permeate bottle though a cooler and recirculated in the shell side $(d=2.1 \mathrm{~cm})$ of the membrane module in a countercurrent mode, at a flow rate of $20 \mathrm{~L} \mathrm{~h}^{-1}$. Both feed and permeate were recirculated back to their reservoirs, after passing through the contactor. The temperature was measured at the membrane inlet and outlet at the feed $\left(T_{\mathrm{F}}\right)$ and permeate $\left(T_{\mathrm{P}}\right)$ sides, where $T_{\mathrm{F} 1}>T_{\mathrm{F} 2}$ and $T_{\mathrm{P} 1}>T_{\mathrm{P} 2}$.

\section{Degradation experiments}

In batch tests performed to develop mathematical model, $200 \mathrm{~mL}$ of BPA solution ( $10 \mathrm{mg} \mathrm{L}^{-1}$ in deionized water) was poured in a $500 \mathrm{~mL}$ three neck round bottom flask immersed in an oil bath. The solution was heated under reflux to given temperature. After reaching set temperatures of 30 , $45,50,55,60$. and $65^{\circ} \mathrm{C}$ in each experiment, the perovskite was added to reach concentration of $0.5 \mathrm{~g} \mathrm{~L}^{-1}$ and the $\mathrm{pH}$ was adjusted to 7.0. Solution was continuously stirred and samples were taken on regular time intervals. To determine kinetic constant rates for different catalyst concentration the same experiment was performed in temperature $65^{\circ} \mathrm{C}$ and the proper amount of perovskite was added each time to reach concentration of 0.15 , $0.35,0.75$, and $1 \mathrm{~g} \mathrm{~L}^{-1}$, respectively. The rate constant, $k$, values were determined for each temperature from the slope of the curve obtained when $-\ln \left(C_{t} / C_{0}\right)$ was plotted with respect to time. Results obtained from both experiments were used to determine our model and are described in the Supplementary material.

To determine the effectiveness of perovskite in degradation of BPA in the catalytic MD process, the experiment described in the following was performed. $1800 \mathrm{~mL}$ of feed solution containing BPA of concentration of $10 \mathrm{mg} \mathrm{L}^{-1}$ was prepared. The permeate initial volume consisted of $300 \mathrm{~mL}$ of distilled water. The volume of dead water needed to start the process was $200 \mathrm{~mL}$. The feed was heated to $65^{\circ} \mathrm{C}$ and the proper amount of perovskite was added to obtain concentration of $1 \mathrm{gL}^{-1}$. The $\mathrm{pH}$ was adjusted to 7.0 and the solution was under continuous stirring. The samples of feed and permeate were taken on regular intervals. For the experiment studying effectiveness of catalyst reuse in thermocatalytic MD process, the same procedure was repeated as described above, but the amount of catalyst needed to reach concentration of $1 \mathrm{~g} \mathrm{~L}^{-1}$ was added only in the first cycle. After addition, the solution of feed was heated to $65^{\circ} \mathrm{C}$, BPA was added at the beginning of each cycle to reach concentration of $10 \mathrm{~g} \mathrm{~L}^{-1}$ and $\mathrm{pH}$ was adjusted to 7.0. The procedure was repeated four times. In each experiment, collected samples were filtered using RC $0.45 \mu \mathrm{m}$ syringe filters. Then, the liquid phases were analyzed through HPLC with UV detection (Summit-Dionex, with a Luna $5 \mathrm{u}$ C18 $100 \AA$ column $(250 \times 4.60 \mathrm{~mm})$, mobile phase flow of $1 \mathrm{~mL} \mathrm{~min}{ }^{-1}$ (acetonitrile/water $=60 / 40$ ), UV detector at $230 \mathrm{~nm}$ ) in order to determine the concentration of the contaminant in the sample. A calibration curve was determined using several solutions of BPA in concentrations between 1 and $10 \mathrm{mg} \mathrm{L}^{-1}$.

\section{DATA AVAILABILITY}

The datasets generated during the current study are available from the corresponding author on reasonable request.

Received: 27 March 2020; Accepted: 29 June 2020; Published online: 17 July 2020

\section{REFERENCES}

1. Schwarzenbach, R. P. et al. The challenge of micropollutants in aquatic systems. Science 5790, 1072-1077 (2006).

2. Werber, J. R., Osuji, C. O. \& Elimelech, M. Materials for next-generation desalination and water purification membranes. Nat. Rev. Mater. 1, 16018 (2016).

3. Kim, S. et al. Removal of contaminants of emerging concern by membranes in water and wastewater: a review. Chem. Eng. J. 335, 896-914 (2017).

4. Alvarez, P. J. J., Chan, C. K., Elimelech, M., Halas, N. J. \& Villagrán, D. Emerging opportunities for nanotechnology to enhance water security. Nat. Nanotechnol. 13, 634-641 (2018).

5. Serna-Galvis, E. A. et al. Degradation of seventeen contaminants of emerging concern in municipal wastewater effluents by sonochemical advanced oxidation processes. Water Res. 154, 349-360 (2019).

6. Nawaz, T. \& Sengupta, S. Contaminants of emerging concern: occurrence, fate, and remediation. In Advances in Water Purification Techniques (ed Ahuja, S.) 67-114 (Elsevier, 2019).

7. Bell, C. H. et al. Emerging Contaminants Handbook (CRC Press, 2019).

8. Fagan, R., McCormack, D. E., Dionysiou, D. D. \& Pillai, S. C. A review of solar and visible light active $\mathrm{TiO}_{2}$ photocatalysis for treating bacteria, cyanotoxins and contaminants of emerging concern. Mater. Sci. Semicond. Process. 42, 2-14 (2016).

9. Żyłła, R., Boruta, T., Gmurek, M., Milala, R. \& Ledakowicz, S. Integration of advanced oxidation and membrane filtration for removal of micropollutants of emerging concern. Process Saf. Environ. Prot. 130, 67-76 (2019).

10. García Doménech, N., Purcell-Milton, F. \& Gun'ko, Y. K. Recent progress and future prospects in development of advanced materials for nanofiltration. Mater. Today Commun. 23, 100888 (2020).

11. Abdel-Fatah, M. A. Nanofiltration systems and applications in wastewater treatment: review article. Ain Shams Eng. J. 9, 3077 (2018).

12. $\mathrm{Li}, \mathrm{N}$. et al. Comparing the performance of various nanofiltration membranes in advanced oxidation-nanofiltration treatment of reverse osmosis concentrates. Environ. Sci. Pollut. Res. 26, 17472-17481 (2019).

13. Junussova, L. R. \& Chicherin, S. V. Wastewater treatment and application in the advanced nanofiltration system. IOP Conf. Ser. Earth Environ. Sci. 408, 012024 (2020).

14. Mayyahi, A. Al. \& Al-asadi, H. A. A. Advanced oxidation processes (AOPs) for wastewater treatment and reuse: a brief review. AJAST 2, 18-30 (2018).

15. Wang, J. A. Advanced oxidation processes for wastewater treatment: formation of hydroxyl radical and application. Crit. Rev. Environ. Sci. Technol. 42, 251-325 (2015).

16. Espíndola, J. C. et al. Performance of hybrid systems coupling advanced oxidation processes and ultrafiltration for oxytetracycline removal. Catal. Today 328, 274-280 (2019).

17. Hodges, B. C., Cates, E. L. \& Kim, J.-H. Challenges and prospects of advanced oxidation water treatment processes using catalytic nanomaterials. Nat. Nanotechnol. 13, 642-650 (2018).

18. Żyłła, R. \& Kos, L. Application of Fenton reaction and nanofiltration for the recovery of process water. Fibres Text. East. Eur. 27, 101-106 (2019).

19. Gallego-Schmid, A. et al. Environmental assessment of solar photo-Fenton processes in combination with nanofiltration for the removal of micro-contaminants from real wastewaters. Sci. Total Environ. 650, 2210-2220 (2019).

20. Zhao, J., Ouyang, F., Yang, Y. \& Tang, W. Degradation of recalcitrant organics in nanofiltration concentrate from biologically pretreated landfill leachate by ultraviolet-Fenton method. Sep. Purif. Technol. 235, 116076 (2020). 
21. Lv, Y. et al. Photocatalytic nanofiltration membranes with self-cleaning property for wastewater treatment. Adv. Funct. Mater. 27, 1700251 (2017).

22. Janssens, R. et al. Coupling of nanofiltration and UV, UV/TiO $\mathrm{T}_{2}$ and $\mathrm{UV} / \mathrm{H}_{2} \mathrm{O}_{2}$ processes for the removal of anti-cancer drugs from real secondary wastewater effluent. J. Environ. Chem. Eng. 7, 103351 (2019).

23. lervolino, G., Zammit, I., Vaiano, V. \& Rizzo, L. Limitations and prospects for wastewater treatment by UV and visible-light-active heterogeneous photocatalysis: a critical review. Top. Curr. Chem. 378, 7 (2020).

24. Nan, M., Jin, B., Chow, C. W. K. \& Saint, C. Recent developments in photocatalytic water treatment technology: a review. Water Res. 44, 2997-3027 (2010).

25. Quist-Jensen, C. A. et al. Direct contact membrane distillation for the concentration of clarified orange juice. J. Food Eng. 187, 37-43 (2016).

26. Tijing, L. D. et al. Fouling and its control in membrane distillation-a review. J. Memb. Sci. 475, 215-244 (2015)

27. Wang, Y. et al. Role of oxygen vacancies and $\mathrm{Mn}$ sites in hierarchical $\mathrm{Mn}_{2} \mathrm{O}_{3} /$ $\mathrm{LaMnO}_{3-\delta}$ perovskite composites for aqueous organic pollutants decontamination. Appl. Catal. B 245, 546-554 (2019).

28. Leiw, M. Y. et al. Dark ambient degradation of bisphenol A and Acid Orange 8 as organic pollutants by perovskite $\mathrm{SrFeO}_{3-\delta}$ metal oxide. J. Hazard. Mater. 260, 1-8 (2013)

29. Deganello, F., Liotta, L. F., Longo, A., Casaletto, M. P. \& Scopelliti, M. Cerium effect on the phase structure, phase stability and redox properties of Ce-doped strontium ferrates. J. Solid State Chem. 179, 3406-3419 (2006).

30. Deganello, F., Liotta, L. F., Leonardi, S. G. \& Neri, G. Electrochemical properties of Ce-doped $\mathrm{SrFeO}_{3}$ perovskites-modified electrodes towards hydrogen peroxide oxidation. Electrochim. Acta 190, 939-947 (2016).

31. Tummino, M. L., Laurenti, E., Deganello, F., Bianco Prevot, A. \& Magnacca, G. Revisiting the catalytic activity of a doped $\mathrm{SrFeO}_{3}$ for water pollutants removal: effect of light and temperature. Appl. Catal. B 207, 174-181 (2017).

32. Dudziak, M. et al. Elimination of bisphenol $A$ from wastewater through membrane filtration processes. J. Ecol. Eng. 19, 69-74 (2018).

33. Zhang, K. et al. Degradation of bisphenol-A using ultrasonic irradiation assisted by low-concentration hydrogen peroxide. J. Environ. Sci. 23, 31-36 (2011).

34. Alkhudhiri, A., Darwish, N. \& Hilal, N. Membrane distillation: a comprehensive review. Desalination 287, 2-18 (2012).

35. Zhang, Y., Rottiers, T., Meesschaert, B., Pinoy, L. \& Van der Bruggen, B. Wastewate treatment by renewable energy driven membrane processes. In Current Trends and Future Developments on (Bio-) (eds Basile, A., Cassano, A. \& Figoli, A.) Membranes. 1-19 (Elsevier, 2019).

36. Deganello, F. \& Tyagi, A. K. Solution combustion synthesis, energy and environment: best parameters for better materials. Prog. Cryst. Growth Charact. Mater. 64, 23-61 (2018).

37. Abo, R., Kummer, N. \& Merkel, B. J. Optimized photodegradation of bisphenol A in water using $\mathrm{ZnO}, \mathrm{TiO}_{2}$ and $\mathrm{SnO}_{2}$ photocatalysts under UV radiation as a decontamination procedure. Drink. Water Eng. Sci. 9, 27-35 (2016).

38. Chiang, K., Lim, T. M., Tsen, L. \& Lee, C. C. Photocatalytic degradation and mineralization of bisphenol A by $\mathrm{TiO}_{2}$ and platinized $\mathrm{TiO}_{2}$. Environ. Sci. Technol. 261, 225-237 (2004).

39. Mahlambi, M. M., Ngila, C. J. \& Mamba, B. B. Recent developments in environmental photocatalytic degradation of organic pollutants: the case of titanium dioxide nanoparticles-a review. J. Nanomater. 2015, 790173 (2015).

40. Dükkancı, M. Degradation of bisphenol-a using a sonophoto Fenton-like hybrid process over a $\mathrm{LaFeO}_{3}$ perovskite catalyst and a comparison of its activity with that of $\mathrm{a} \mathrm{TiO}_{2}$ photocatalyst. Turk. J. Chem. 40, 784-801 (2016).

41. Dong, H., Zeng, G., Tang, L. \& Fan, C. An overview on limitations of $\mathrm{TiO}_{2}$-based particles for photocatalytic degradation of organic pollutants and the corresponding countermeasures. Water Res. 79, 128-146 (2015).

42. Reddy, P. V. L. et al. Photocatalytic degradation of bisphenol A in aqueous media: a review. J. Environ. Manag. 213, 189-205 (2018)

43. Jia, Y. et al. Nitrogen doped $\mathrm{BiFeO}_{3}$ with enhanced magnetic properties and photo-Fenton catalytic activity for degradation of bisphenol $A$ under visible light. Chem. Eng. J. 337, 709-721 (2018).

44. Dükkancl, M. Sono-photo-Fenton oxidation of bisphenol-A over a $\mathrm{LaFeO} 3$ perovskite catalyst. Ultrason. Sonochem. 40, 110-116 (2018)

45. Deshmukh, A. et al. Membrane distillation at the water-energy nexus: limits, opportunities, and challenges. Energy Environ. Sci. 11, 1177-1196 (2018).

46. Moran Ayala, L. I. et al. Water defluoridation: nanofiltration vs. membrane distillation. Ind. Eng. Chem. Res. 57, 14740-14748 (2018).
47. Lazar, M. A., Varghese, S. \& Nair, S. S. Photocatalytic water treatment by titanium dioxide: recent updates. Catalysis 4, 572-601 (2012).

48. Garg, A. et al. Photocatalytic degradation of bisphenol-A using N, Co codoped $\mathrm{TiO}_{2}$ catalyst under solar light. Sci. Rep. 9, 765 (2019).

49. Kuo, C. Y., Wu, C. H. \& Lin, H. Y. Photocatalytic degradation of bisphenol A in a visible light $/ \mathrm{TiO}_{2}$ system. Desalination 256, 37-42 (2010).

50. Gao, B., Lim, T. M., Subagio, D. P. \& Lim, T. T. Zr-doped $\mathrm{TiO}_{2}$ for enhanced photocatalytic degradation of bisphenol A. Appl. Catal. A Gen. 375, 107-115 (2010).

51. Jia, C., Qin, Q., Wang, Y. \& Zhang, C. Photocatalytic degradation of bisphenol A in aqueous suspensions of titanium dioxide. Adv. Mater. Res. 433-440, 172-177 (2012).

52. Chen, H., Jiangang, K. \& Wang, L. Thermal catalysis under dark ambient conditions in environmental remediation: fundamental principles, development, and challenges. Chin. J. Catal. 40, 1117-1134 (2019).

\section{ACKNOWLEDGEMENTS}

This paper is part of a project that has received funding from the European Union's Horizon 2020 research and innovation program under the Marie Skłodowska-Curie grant agreement No. 765860 .

\section{AUTHOR CONTRIBUTIONS}

V.B. conceived the concept, C.A.Q.-J. designed and built the MD setup and help designing experiments; K.J., F.E.B.C., and F.H. carried out materials synthesis and permeation tests. K.J., F.H., M.K.J., and V.B. analyzed data. F.E.B.C., F.D., and G.M performed material characterization. M.K.J. and K.J. developed a model for the catalytic membrane distillation system; K.J. wrote the paper with editorial contributions from V.B., M.K.J., F.D., F.E.B.C., C.A.Q.-J., and G.M.

\section{COMPETING INTERESTS}

The authors declare no competing interests.

\section{ADDITIONAL INFORMATION}

Supplementary information is available for this paper at https://doi.org/10.1038/ s41545-020-00082-2.

Correspondence and requests for materials should be addressed to V.B.

Reprints and permission information is available at http://www.nature.com/ reprints

Publisher's note Springer Nature remains neutral with regard to jurisdictional claims in published maps and institutional affiliations.

Attribution 4.0 International License, which permits use, sharing, adaptation, distribution and reproduction in any medium or format, as long as you give appropriate credit to the original author(s) and the source, provide a link to the Creative Commons license, and indicate if changes were made. The images or other third party material in this article are included in the article's Creative Commons license, unless indicated otherwise in a credit line to the material. If material is not included in the article's Creative Commons license and your intended use is not permitted by statutory regulation or exceeds the permitted use, you will need to obtain permission directly from the copyright holder. To view a copy of this license, visit http://creativecommons org/licenses/by/4.0/.

(c) The Author(s) 2020 